\title{
PROGRAM EXPANDING MATERNAL AND NEONATAL SURVIVAL (EMAS) DI LINGKUNGAN DINAS KESEHATAN KABUPATEN KARAWANG
}

\author{
Sartika Dewi \\ Universitas Buana Perjuangan Karawang \\ Email: sartikadewi@ubpkarawang.ac.id
}

\begin{abstract}
Abstrak
Program Expanding Maternal and Neonatal Survival (EMAS) merupakan program hasil kerja sama antara Pemerintah Indonesia dengan lembaga donor united states agency international development (USAID), yang bertujuan untuk menurunkan AKI dan AKB di Indonesia sebesar 25\%. Penelitian ini bertujuan untuk mengetahui implementasi Program Expanding Maternal and Neonatal Survival (EMAS) di Lingkungan Dinas Kesehatan Kabupaten Karawang. Penelitian ini dilakukan di Dinas Kesehatan Karawang, pendekatan yang digunakan dalam penelitian ini adalah yuridis normatif dengan menggambarkan dan menganalisa masalah yang ada serta termasuk dalam jenis penelitian normatif yang akan disajikan secara deskriptif. Hasil penelitian ini menjelaskan pelaksanaan program EMAS yang sudah meningkatkan kualitas pelayanan obstetri dan neonatal esensial dasar (PONED) dan pelayanan obstetri dan neonatal esensial komprehensif (PONEK) dengan memastikan intervensi medis prioritas yang mempunyai dampak besar pada penurunan kematian yang diterapkan di Rumah Sakit dan Puskesmas serta meningkatkan efektifitas dan efisiensi sistem rujukan antar Puskesmas dan Rumah Sakit Hasil akhir yang ingin dicapai dari Program EMAS ini ialah adanya penurunan angka kematian ibu (AKI) dan angka kematian bayi (AKB).
\end{abstract}

Kata Kunci: Program EMAS, Kematian, Ibu Dan Bayi

Abstract
The Maternal and Neonatal Survival Expanding Program is a collaboration program between the Government of
Indonesia and the United States International Development Agency (USAID), which aims to reduce MMR and IMR
in Indonesia by 25\%. This study aims to determine the implementation of the Maternal and Neonatal Survial
Expanding Program in the Karawang District Health Office. This research was conducted at the Karawang Health
Office, the method used in this research was analytical descriptive which is a research to describe and analyze
existing problems and included in the type of library research that will be presented descriptively. The results of this
study explain that the implementation of the EMAS program has improved the quality of basic essential obstetric
and neonatal services and comprehensive essential obstetric and neonatal services by ensuring priority medical
interventions that have a large impact on reducing mortality implemented in hospitals and health centers and
increasing effectiveness and the efficiency of the referral system between health centers of public and Hospitals The
final outcome to be achieved from the EMAS Program is a decrease in maternal mortality rate (MMR) and infant
mortality rate (IMR).

Keywords: EMAS Program, Death, Mother and Baby. 


\section{PENDAHULUAN}

\begin{tabular}{lcr}
\multicolumn{2}{c}{ Pembangunan } & kesehatan \\
merupakan salah satu & upaya \\
pemerintah & Indonesia & dalam \\
pembangunan & nasional & untuk
\end{tabular}

meningkatkan kesadaran, kemauan dan kemampuan hidup sehat bagi setiap orang agar terwujud derajat kesehatan masyarakat yang optimal. Pembangunan kesehatan juga merupakan salah satu upaya utama untuk meningkatkan kualitas sumber daya manusia yang pada gilirannya mendukung percepatan pencapaian sasaran pembangunan nasional. ${ }^{1}$ Program expanding, maternal, and newborn survival (EMAS) merupakan program hasil kerja sama antara Pemerintah Indonesia dengan lembaga donor united states agency internatio nal development (USAID), yang bertujuan untuk menurunkan $\mathrm{AKI}$ dan AKB di Indonesia.

Untuk mencapai target tersebut, program EMAS akan dilaksanakan di provinsi dan kabupaten dengan jumlah kematian yang besar, yaitu Sumatera Utara, Banten, Jawa Barat,

1 Yanti dan Nurul Eko, Etika Profesi kesehatan, Pustaka Rihama, Yogyakarta, 2010. HIm 7
Jawa Tengah, Jawa Timur, dan Sulawesi Selatan, dimana pada tahun pertama akan dilaksanakan pada 10 kabupaten. $^{2}$

Kementrian Kesehatan telah mengembangkan serangkaian model terobosan berbasis tekhnologi informasi dan komunikasi guna meningkatkan kualitas layanan komplikasi kegawatdaruratan ibu dan bayi serta meningkatkan efisiensi dan efektivitas sistem rujukan. Oleh sebab itu, Kementrian Kesehatan memberikan terobosan terbaru dalam penangananan kasus kematian ibu dan bayi yaitu dengan meluncurkan program EMAS (expanding, maternal, and newborn survival) dengan model sistem informasi yang dikembangkan meliputi : sistem informasi penguat dan pembelajaran informasi (SIPPP), sistem informasi gerbang aspirasi pelayanan kesehatan publik (SIGAPKU), dan sistem informasi jejaring rujukan

\footnotetext{
${ }^{2}$ http://www.medanbisnisdaily.com/news/rea d/2013/03/20/18924/program-emas-bentukracl
} 
kegawatdaruratan ibu dan neonatal (SIJARIEMAS). ${ }^{3}$

\section{PERMASALAHAN}

Berdasarkan hal-hal yang telah diungkapkan dalam latar belakang, maka dibuat rumusan masalah sebagai berikut:

1. Apa yang dimaksud dengan Program Expanding Maternal and Neonatal Survial (EMAS)?

2. Bagaimana cara kerja Program Expanding Maternal and Neonatal Survial (EMAS) di Dinas Kesehatan Karawang ?

\section{METODE PENELITIAN}

Penelitian ini menggunakan metode yuridis normatif yaitu dengan mengkaji atau menganalisis data skunder yang berupa bahan-bahan hukum sekunder dengan memahami hukum sebagai penelitian kepustakaan, yaitu penelitian terhadap data sekunder. ${ }^{4}$

Sumber Data dapat diklasifikasikan berdasarkan sifat

\footnotetext{
${ }^{3}$ http://m.liputan6.com/health/read/475795/k ematian-ibu-dan-anak-di-jawa-baratmasih-yangtertinggi

${ }^{4}$ Soejorno Soekanto dan Sri Madmudji, Penelitian Hukum Normatif, Suatu
}

data dan sumber data. Berdasarkan sifatnya, data dapat diklasifikasikan menjadi data kualitatis dan kuantitatif. Sedangkan berdasarkan sumbernya, data dapat diklasifikasikan menjadi data primer dan data sekunder. ${ }^{5}$ Data yang dipergunakan dalam penulisan ini, yaitu data primer dan data sekunder dan yang berdasarkan sifatnya adalah data kualitatif.

1. Data primer, yaitu data yang diperoleh langsung dari hasil pengamatan di lapangan, berupa hasil dari wawancara atau interview. Data primer dugunakan untuk menjawab permasalahan mengenai penyelesaian sengketa melalui mediasi. Sumber data primer diperoleh dengan wawancara terhadap: Petugas SIJARIEMAS di Dinas Kesehatan Karawang

2. Data sekunder adalah data yang diperoleh melalui studi kepustakaan dan dokumentas, antara lain berasal dari bahan

Tinjauan Singkat, Rajawali, Jakarta 1985, hlm 15.

${ }^{5}$ Soekidjo Notoatmodjo, Metodologi Penelitian Kesehatan, Rineka Cipta, Jakarta,2005. hlm. 70. 
hukum primer, bahan hukum sekunder dan bahan hukum tersier.

Sesuai dengan penggunaan data sekunder dalam penelitian ini, maka pengumpulan data yang dilakukan dengan mengumpulkan, mengkaji, dan mengelola secara sistematis bahan-bahan kepustakaan serta dokumen yang berkaitan. Data sekunder baik yang menyangkut bahan hukum primer, sekunder, diperoleh dari bahan pustaka, dengan memperhatikan prinsip pemutakhiran dan relevansi. ${ }^{6}$

\section{HASIL DAN PEMBAHASAN}

\section{A. Program (Explanding maternal} and neonatal survival) EMAS

\section{Pengertian}

EMAS (Explanding maternal and neonatal survival) adalah sebuah program kerjasama Kementrian Kesehatan RI dan USAID selama lima tahun (2012-2016) dalam rangka mengurangi angka kematian ibu dan bayi baru lahir. Konsep Pendampingan Program EMAS dibuat dan disepakati bersama antara Program EMAS,

USAID,
Kementerian Kesehatan RI, Dinas Kesehatan Provinsi dan Organisasi Profesi terkait. Dalam pelaksanaannya pendampingan Program EMAS dilaksanakan oleh 5 organisasi yang mendapatkan mandate, yaitu Jhpiego, afiliasi Johns Hopkins University, Rumah Sakit Budi Kemuliaan, Organisasi Islam Muhammadiyah, Save The Children dan Research Triangle Institute (RTI). Ke 5 organisasi tsb, melalui staf yang bekerja di Program EMAS Provinsi Jawa Barat, bekerjasama dgn DinasKesehatan Provinsi Jawa Barat, Pemda Provinsi Jawa Barat, Organisasi Profesi terkait di Provinsi Jawa Barat dan stakeholders lainnya yang tergabung dalam Tim Koordinasi Penyelamatan Ibu dan bayi baru lahir Provinsi Jawa Barat (SK Gubernur Jawa Barat no 441.8/Kep.1076-Dinkes/2014), memilih Kabupaten kabupaten dengan jumlah kematian Ibu dan bayi yang tinggi, serta memiliki sumberdaya yang cukup dan komitmen pemda setempat yang tinggi, untuk dijadikan sebagai

\footnotetext{
${ }^{6}$ Burhan Ashofa, Metode Penelitian Hukum, Rieneka Cipta, Jakarta, 2002. hlm 34
} 
Kabupaten percontohan yang akan mendapatkan pendampingan dari program EMAS, dimana salah satunya adalah Kabupaten Karawang. ${ }^{7}$

\section{Tujuan Program EMAS}

Explanding maternal and neonatal bertujuan untuk :

a. Meningkatkan kualitas pelayanan PONED \& PONEK. Memastikan intervensi medis prioritas yang mempunyai dampak besar pada penurunan kematian diterapkan di RS dan Puskesmas. Pendekatan tata kelola klinis (clinical governance) diterapkan di RS dan Puskesmas.

b. Meningkatkan efektifitas dan efisiensi sistem rujukan antar Puskesmas/Balkesmas dan RS. Penguatan sistim rujukan.

c. Meningkatkan peran serta masyarakat dalam menjamin akuntabilitas dan kualitas nakes, faskes dan Pemda. Meningkatkan akses masyarakat dalam memanfaatkan pelayanan kesehatan.

\section{Pelaksanaan Program} EMAS

EMAS dilaksanakan dalam enam provinsi yang memiliki jumlah kematian ibu dan neonatal besar. Enam Provinsi tersebut adalah:

a. Sumatera Utara daerah intervensi nya adalah Kabupaten Deli Serdang. Kabupaten di sekitar daerah intervensi adalah Kota Medan, Kota Tebingtinggi, Kab Langkat, Kab Karo, Kota Pematangsiantar, Kab Serdang Bedagai, Kab Simalungun, Kota Binjai.

b. Banten daerah intervensinya adalah Kabupaten Serang. Kabupaten di sekitar daerah intervensi adalah Kab Tangerang, Kab Lebak, Kab Pendeglang, dan Kota Cilegon.

${ }^{7}$ SK Gubernur Jawa Barat no 
c. Jawa Barat daerah

tengah

adalah

intervensinya adalah

Kabupaten Banyumas.

Kabupaten Bandung.

Kabupaten di sekitar

Kabupaten di sekitar

daerah intervensi adalah

Kab Garut, Kab

daerah intervensi adalah

Kab Kebumen, Kab

Sumedang,

$\mathrm{Kab}$

Cilacap,

$\mathrm{Kab}$

Karawang, Kab Subang,

Purbalingga,

$\mathrm{Kab}$

Kab Purwakarta, Kab

Cianjur, Kota Bandung,

Kota Cimahi, Kab

Bandung Barat. Daerah

intervensi lain di Jawa

Barat

adalah

Kabupaten Cirebon.

Kabupaten di sekitar

daerah intervensi adalah

Kota Cirebon, Kab

Indramayu, $\quad \mathrm{Kab}$

Majalengka, Kab

Kuningan.

d. Jawa Tengah daerah intervensinya adalah

Kabupaten Tegal.

Kabupaten di sekitar

daerah intervensi

adalah Kota Tegal, Kab

Brebes, Kab Pemalang,

Kab Pekalongan, dan

Kota Pekalongan. Daerah

intervensi lain di Jawa

Banjarnegara.

e. Jawa Timur daerah intervensinya adalah Kabupaten Malang. Kabupaten di sekitar daerah intervensi adalah Kota Malang, Kab Lumajang, Kab Probolinggo, Kab Pasuruan, Kota Batu, Kab Blitar.

f. Sulawesi Selatan. Daerah intervensinya adalah Kabupaten Pinrang. Kabupaten di sekitar daerah intervensi adalah Kab Tana Toraja, Kab Enrekang, Kab Sidenreng Rappang, Kota Pare-Pare.

\section{Pendekatan program} EMAS dilakukan melalui :

1) Meningkatkan kualitas pelayanan emergensi obstetri dan neonatal 
melalui penerapan tata kelola yang baik terkait kelangsungan hidup ibu dan bayi baru lahir.

2) Memperkuat sistem rujukan yang efisien dan efektif antar Puskesmas dan RS c. Pemanfaatan teknologi informasi mutakhir (SMS, hotline, media social) untuk meningkatkan efektifitas dan efisiensi dalam pelayanan

kegawatdaruratan

kesehatan ibu dan bayi baru lahir

3) Program dirancang agar dapat memberi dampak nasional (tidak hanya sebatas area kerja). Lima Strategi Program EMAS adalah Strategi Program EMAS adalah Laser Focus, yaitu:

1) Penanganan

$$
\begin{aligned}
& \text { penyebab utama } \\
& \text { kematian ibu } \\
& \text { (perdarahan, eklamsi } \\
& \text { dan infeksi) dan } \\
& \text { kematian neonatal }
\end{aligned}
$$

rendah/prematuritas

\&

sepsis).

(asfiksia, bayi berat lahir.

2) Peningkatan clinical governance yaitu suatu rangka/ struktur melalui organisasi pelayanan kesehatan nasional berupa tanggung jawab peningkatan kualitas pelayanan yang berkelanjutan dan standar asuhan dengan tingkat keamanan tinggi yang akan menciptakan asuhan klinis berkualitas.

3) Penerapan good governance untuk meningkatkan pengawasan dari masyarakat madani

4) Membangun jejaring fasilitas pelayanan kesehatan publik dan swasta

5) Penggunaan teknologi informasi 
dan komunikasi untuk

memperbaiki rujukan.

4) Pelaksanaan Program

EMAS Di daerah

Network

yang melaksanakan

Program EMAS,

dibentuk Vanguard

yaitu sistem rujukan

antara 1 RSUD, 2-3 RS

Swasta, dan 5-10

Puskesmas. Dalam sistem

ini, dipilih $\mathrm{RS}$ dan

Puskesmas yang sudah

cukup kuat agar

membangun jejaring dan

dapat membimbing

jaringan Kabupaten yang

lain dengan melibatkan

RS/RB swasta untuk memperkuat jejaring sistim rujukan di daerah.

Untuk itu diperlukan Kerjasama yang baik antara Dinas Kesehatan dengan Rumah Sakit.

Dengan pembentukan Vanguard Network, maka daerah di sekitar wilayah intervensi pun akan

mendapat kemudahan

dalam sistem rujukan.

5) Melibatkan $\quad \mathrm{RS} / \mathrm{RB}$

swasta untuk

memperkuat jejaring

sistem rujukan di daerah.

6) Implementasi Kebijakan

Program EMAS

Implementasi program

mengikutsertakan upaya

policy makers (pembuat

kebijakan) untuk

mempengaruhi perilaku

birokrat pelaksana agar

bersedia memberikan

pelayanan dan perilaku

pemberi pelayanan. $^{8}$

\section{B. Cara Kerja Program EMAS}

Program

\section{SIJARIEMAS}
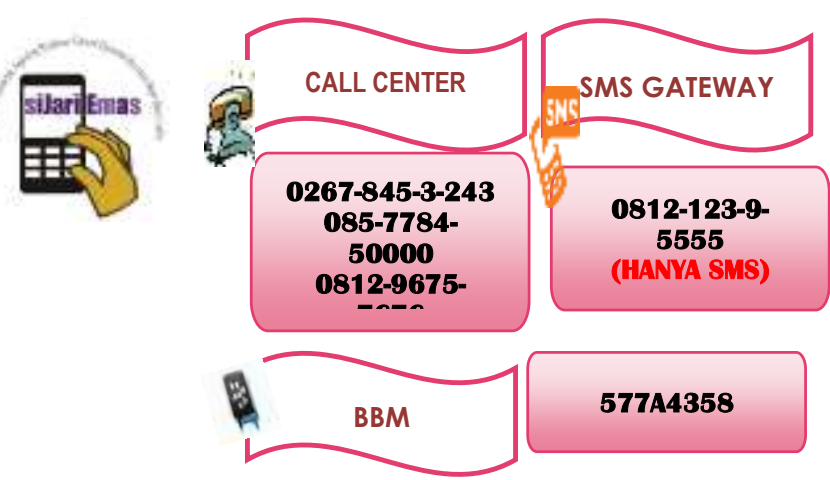

${ }^{8}$ Doc Dinas Kesehatan Karawang BUKU I,

Pengantar SIJARIEMAS 


\section{Pengantar}

Sistem Informasi Jejaring Rujukan Maternal dan Neonatal (SIJARIEMAS) merupakan sistem informasi dengan fungsi utama untuk komunikasi pertukaran rujukan gawat darurat dan rujukan terencana bagi kasus maternal dan neonatal di dalam jejaring rujukan fasilitas kesehatan yang telah berjejaring. Pemanfaatan SIJARIEMAS dapat meningkatkan kesiapan dari pihak Rumah Sakit untuk menerima rujukan, memberdayakan fungsi Puskesmas mampu PONED untuk penanganan kasus tertentu, mencegah terjadinya multiple referral, membangun komunikasi dan rujukan ilmu antara Bidan, Puskesmas dan Rumah Sakit, serta menjadi basis data untuk perencanaan dan pengambilan keputusan di RS maupun DINKES. ${ }^{9}$

Media komunikasi yang digunakan pada SIJARIEMAS ada tiga macam, yaitu SMS (short message service), telepon, dan internet. Ketiga media komunikasi ini digunakan secara simultan sedemikian hingga tercapai efektivitas dan efisiensi komunikasi dalam penanganan kasus kegawatdaruratan ibu dan bayi baru lahir.

Karena SIJARIEMAS digunakan sebagai sistem informasi dalam jejaring fasilitas kesehatan, penggunanya juga berada di lokasi berbeda di berbagai fasilitas kesehatan yang telah berjejaring tersebut. Mulamula, informasi rujukan dikirim oleh tenaga kesehatan (nakes) yang akan merujuk pasien. Nakes yang akan merujuk pasien bisa berprofesi sebagai dokter, bidan,

\footnotetext{
${ }^{9}$ Doc Dinkes Karawang Buku II, Pedoman Langkah-langkah Penggunaan SIJARIEMAS.
} 
atau perawat di puskesmas, klinik kesehatan, rumah sakit, atau lokasi praktek mandiri. Informasi permintaan rujukan dan data rujukan dikelola oleh petugas kesehatan di rumah intalasi gawat darurat, bagian maternal, dan atau bagian perinatal rumah sakit.

\section{Sistem Rujukan Program EMAS:}

a. SIJARIEMAS (Sistem Informasi dan Komunikasi Jejaring Rujukan Maternal dan Neonatal) adalah Sistem informasi dan komunikasi timbal balik dengan menggunakan pesan singkat elektronik (SMS), telepon dan atau Internet antara petugas pelayanan kesehatan dasar (Bidan Praktek Mandiri, bidan/dokter Puskesmas PONED, bidan/dokter Puskesmas Non-PONED, bidan Rumah Bersalin) dengan rumah sakit dalam jejaring rujukan kegawatdaruratan maternal dan neonatal. b. Petugas pelayanan kesehatan adalah staf fasilitas kesehatan yang memberikan layanan kesehatan ibu dan bayi baru lahir. Petugas Pelayanan Kesehatan termasuk Bidan Desa, Bidan Puskesmas, Bidan Praktek Swasta (BPS) dan Dokter Praktek Swasta (DPS).

c. Rumah Sakit Rujukan adalah rumah sakit yang siap memberikan layanan 24 jam layanan rujukan ibu dan bayi baru lahir.

d. Operator SIJARIEMAS adalah staf di Rumah Sakit Rujukan yang bertanggung jawab dan atau diberi tugas menjawab dan mengelola informasi rujukan melalui SIJARIEMAS.

\section{Tujuan Sistem Rujukan Program EMAS:}

a. Tujuan Umum

Terlaksananya komunikasi untuk meningkatkan akurasi informasi, kelengkapan data dan mempercepat penyampaian informasi rujukan pasien gawat darurat 
maternal neonatal ke rumah sakit rujukan ibu hamil dan bayi baru lahir.

b. Tujuan Khusus :

1) Meningkatkan waktu respon penanganan terhadap pasien gawat darurat materna dan neonatal;

2) Memperoleh informasi rujukan yang lengkap dan akurat secara mudah dan cepat;

3) Menerapkan pertukaran informasi rujukan gawatdarurat maternal dan neonatal sesuai kondisi rumah sakit rujukan dalam jejaring.

4. Pendaftaran data tenaga kesehatan dalam program EMAS

Sebelum mengirim informasi rujukan gawat darurat maupun rujukan terencana melalui SIJARIEMAS, data tenaga kesehatan harus terdaftar terlebih dahulu di dalam database SIJARIEMAS. Dengan kata lain, kiriman informasi permintaan rujukan dari tenaga kesehatan yang belum terdaftar di database SIJARIEMAS tidak dapat diterima oleh sistem.

Untuk melakukan pendaftaran data tenaga kesehatan ke SIJARIEMAS, ada dua cara yang bisa dipilih, yaitu:

\section{a. Pendaftaran Tenaga}

\section{Kesehatan Melalui SMS}

Pendaftaran tenaga kesehatan melalui SMS dilakukan dengan menggunakan telepon genggam milik tenaga kesehatan yang akan didaftarkan. Format SMS pendaftaran data tenaga kesehatan adalah sebagai berikut:

\section{reg\#nama_nakes\#alamat\#pus} kesmas\#profesi

Keterangan:

- reg adalah kata kunci sebagai tanda bahwa SMS yang dikirim adalah pendaftaran tenaga kesehatan

- nama_nakes diisi nama lengkap tenaga kesehatan yang mendaftar 
- alamat diisi alamat tempat tenaga kesehatan SMS tinggal tenaga kesehatan yang mendaftar

- puskesmas, diisi nama puskesmas tempat kerja atau wilayah kerja tenaga kesehatan

- profesi, diisi jenis profesi tenaga keseahatan: bidan, dokter, atau perawat.

Contoh:

reg\#Heni Lestari\#JI. Gerilya No. 23 Banjaran\#Puskesmas Banjaran\#Bidan Desa Geulis

Setelah tenaga kesehatan mengirim SMS pendaftaran, data yang bersangkutan tidak otomatis terdaftar sebagai tenaga kesehatan di database SIJARIEMAS. Data tersebut menunggu verifikasi dari petugas terkait untuk mengecek kebenaran datanya.

Setelah diproses verifikasi data nakes yang didaftarkan dan dinyatakan benar, maka nakes tersebut akan mendapat SMS berisi informasi seperti berikut:

$\begin{array}{rrr}\text { "Selamat } & \text { Anda } & \text { sudah } \\ \text { terdaftar } & \text { dalam } & \text { database }\end{array}$

Gateway. No PIN: 5690"

b. Pendaftaran Tenaga

Kesehatan Melalui

Web/Internet

Selain pendaftaran lewat SMS, tenaga kesehatan yang akan terlibat dalam pengiriman rujukan melalui SIJARIEMAS dapat didaftarkan melaui website SIJARIEMAS. Pendaftaran tenaga kesehatan melalui website SIJARIEMAS bisa dilakukan oleh petugas Administrator atau Operator SIJARIEMAS yang ditunjuk (yang sudah memiliki user name dan password login sebagai administrator).

1) Nyalakan komputer, jika komputer belum menyala. Jika komputer sudah menyala, langsung ke langkah 2.

2) Sambungkan komputer ke Internet, jika belum terhubung. Apabila komputer sudah terhubung ke Internet, langsung ke Langkah 3.

3) Buka aplikasi penjelajahinternet (internet browser). Direkomendasikan 
menggunakan penjelajah Mozilla Firefox.

4) Ketikkan alamat situs SIJARIEMAS kabupaten Anda di Address bar aplikasi penjelajah-internet yang digunakan. Untuk SIJARIEMAS Kabupaten Karawang, alamat situsnya: http://rujukan.karawangka b.go.id

5) Login dengan username dan password user group puskesmas yang Anda miliki.

6) Klik menu Direktori $\rightarrow$ Database Tenaga Kesehatan

7) Klik tombol Data Baru yang ada di sudut kanan atas form

8) Ketikkan informasi mengenai data tenaga kesehatan yang didaftarkan pada form yang tampil.

- Nama, diisi nama tenaga kesehatan

- Telp, diisi nomor telepon genggam/HP （yang memiliki fasilitas SMS)

- Telp Alternatif, diisi nomor telepon genggam/HP (yang memiliki fasilitas SMS)

jika memiliki dua nomor telepon genggam

- Email, diisi alamat email tenaga kesehatan

- Alamat, diisi alamat tempat tinggal tenaga kesehatan

- Alamat Alternatif, diisi jika memiliki alamat alternative, misalnya alamat praktek tenaga kesehatan

- Profesi, dipilih profesi yang sesuai dari daftar yang ada

- Keterangan, diisi keterangan yang diperlukan, misalnya ia merupakan bidan coordinator di puskesmas

- Anggota Komite Medis, klik Ya jika merupakan anggota komite medis atau Tidak jika bukan merupakan anggota komite medis

- Status Kepegawaian, pilih PNS jika tenaga 
kesehatan berstatus

senagai PNS, pilih Swasta

jika ia merupakan tenaga

kesehatan bukan PNS

- Nama Lembaga, pilih nama lembaga tempat kerja tenaga kesehatan atau bekerja di wilayah kerja lembaga kesehatan tersebut

- ETA, singkatan dari estimized time arrival (estimasi waktu kedatangan), diisi perkiaran waktu tempuh dari tempat praktek tenaga kesehatan ke rumah sakit rujukan prioritas pertamanya.

9) Klik tombol Simpan untuk memproses penyimpanan data.

5. Cara merujuk pasien gawat darurat dalam program EMAS Pasien gawat darurat adalah pasien dalam kondisi gawat yang perlu sesegera mungkin ditangani. Setelah memperoleh informasi mengenai pasien yang akan dirujuk, informasi tersebut disampaikan ke SIJARIEMAS untuk memperoleh tanggapan dari IGD rumah sakit yang berada dalam jejaring. Informasi permintaan rujukan dapat dikirim menggunakan SMS (Short Message Services), telepon, atau Internet/web.

\section{a. Mengirim Informasi Rujukan Gawat Darurat dengan SMS}

Salah satu cara mengirim informasi rujukan ke SIJARIEMAS adalah dengan SMS. Cara ini boleh dibilang merupakan cara paling murah. Syarat pengiriman informasi rujukan ke SIJARIEMAS melalui SMS adalah:

- Tersedia telepon genggam dengan nomor yang sudah terdaftar di database tenaga kesehatan di SIJARIEMAS

- Terdapat sinyal dari provider nomor HP yang akan digunakan.

- Panjang SMS maksimal 160 karakter

- Mengikuti format yang telah ditentukan.

- SMS dikirim dengan telepon genggam yang nomornya sudah 
terdaftar di database tenaga kesehatan SIJARIEMAS.

- SMS dikirim ke nomor hotline SMS SIJARIEMAS kabupaten .....

Format SMS pengiriman informasi rujukan pasien gawat darurat dibedakan menjadi dua dengan format yang mirip, sebagai berikut:

Format SMS Rujukan Gawat Darurat Kasus Maternal (Ibu Hamil/Nivas)

\section{r\#kode_praktek\#nama_ibu\#u mur\#suami\#asuransi\#golonga n_darah \\ \#alat_transportasi\#diagnosa\#t indakan_pra_rujukan}

Keterangan:

- $\mathbf{r}$ merupakan penanda bahwa pasien yang akan dirujuk adalah ibu hamil/ibu nivas (kasus maternal)

- kode_praktek diisi 1 jika nakes merupakan nakes yang praktek di puskesmas/rumah sakit, diisi 2 jika nakes merupakan nakes yang melakukan praktek mandiri

- umur dalam tahun ditulis dengan bulangan bulat

- asuransi diisi dengan asuransi yang digunakan pasien. Jika tidak menggunakan asuransi, tulislah “_“ (tanpa tanda kutip).

- golongan_darah ditulis: A, AB, B, atau 0. Jika golongan darah belum diketahui, tulislah “" (tanpa tanda kutip).

- alat_transportasi diisi dengan kendaraan yang akan dipakai membawa pasien, misalnya: ambulan, mobil, becak, sepeda motor, dll.

- diagnosa diisi dengan diagnose pasien, sebisa mungkin lengkap, tetapi jika terlalu panjang harus disingkat

- tindakan_pra_rujukan ditulis tindakan 


\begin{abstract}
stabilisasi atau tindakan medis yang sudah dilakukan terhadap pasien sebelum pasien dirujuk. Sebisa mungkin ditulis lengkap, tetapi jika terlalu panjang harus disingkat.
\end{abstract}

\section{Contoh:}

\begin{tabular}{|l|l|}
\hline \multicolumn{3}{|l|}{ r\#1\#Maimunah\#38\#Amir\#ja } \\
mpersal\#O\#ambulan_desa\#G \\
3P2A1 TD: $\quad$ 180/100 \\
PE\#MgSO4+
\end{tabular}

Jika pengiriman SMS berhasil diterima oleh server SIJARIEMAS, maka Anda akan memperoleh SMS balasan seperti berikut:

\section{Permintaan rujukan Anda} telah diterima.Jika dlm waktu 10 menit tdk ada jawaban,silahkan menghubungi via telepon. ID RUJUKAN: 641

Format SMS Rujukan Gawat Darurat Kasus Neonatal (Bayi) rb\#kode_praktik\#nama_ibu_b ayi\#umur\#nama_ayah_bayi\#a

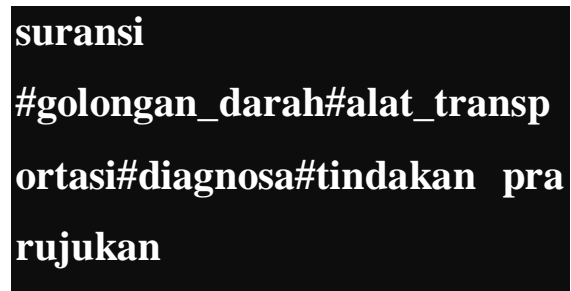

Keterangan:

- rb merupakan penanda bahwa pasien yang akan dirujuk adalah bayi (kasus neonatal)

- kode_praktek diisi 1 jika nakes merupakan nakes yang praktek di puskesmas/rumah sakit, diisi 2 jika nakes merupakan nakes yang melakukan praktek mandiri

- umur dalam satuan hari ditulis dengan bulangan bulat

- asuransi diisi dengan asuransi yang digunakan pasien. Jika tidak menggunakan asuransi, tulislah “_" (tanpa tanda kutip).

- golongan_darah ditulis: A, AB, B, atau 0. Jika golongan darah belum 
diketahui, tulislah “-

“ (tanpa tanda kutip).

- alat_transportasi diisi dengan kendaraan yang akan dipakai membawa pasien, misalnya: ambulan, mobil, becak, sepeda motor, dll.

- diagnosa diisi dengan diagnose pasien, sebisa mungkin lengkap, tetapi jika terlalu panjang harus disingkat

- tindakan_pra_rujukan ditulis tindakan stabilisasi atau tindakan medis yang sudah dilakukan terhadap pasien sebelum pasien dirujuk. Sebisa mungkin ditulis lengkap, tetapi jika terlalu panjang harus disingkat.

Contoh:

rb\#1\#Maimunah\#2\#Amir\#ja mpersal\#O\#ambulan desa\#sepsis \#pemberian antibiotik
Jika pengiriman SMS berhasil diterima oleh server SIJARIEMAS, maka Anda akan memperoleh SMS balasan seperti berikut:

Permintaan rujukan Anda telah diterima.Jika dlm waktu 10 menit tdk ada jawaban,silahkan menghubungi via telepon. ID RUJUKAN: 642

b. Mengirim Informasi Rujukan melalui Telepon

Penyampaian informasi permintaan rujukan ke SIJARIEMAS dapat dilakukan melalui saluran telepon, baik telepon kabel maupun telepon bergerak (mobile phone). Untuk menyampaikan informasi rujukan gawat darurat melalui telepon, silahkan hubungi nomor telepon layanan hotline telepon rumah sakit yang digunakan pada SIJARIEMAS di kabupaten.

Di kabupaten saat ini nomor hotline telepon yang digunakan adalah nomor

Setelah tersambung dan diterima oleh Operator/Petugas, Anda akan ditanya informasi sebagai berikut: 
- Menyebutkan nama dan nomor telepon Anda.

- Menyebutkan asal puskesmas atau nama fasilitas layanan kesehatan dasar tempat Anda bertugas

- Informasi mengenai pasien yang dirujuk, meliputi:

○ Kategori pasien (ibu atau bayi)

- Nama pasien

○ Umur

○ Nama

Penanggungjawab

Pasien

- Golongan darah

- Alat transportasi yang akan digunakan untuk membawa pasien

- Diagnosa pasien

- Tindakan prarujukan (stabilisasi) yang telah dilakukan

○ Asuransi yang digunakan.

Setelah Anda menyampaikan informasi rujukan melalui telepon, maka selanjutnya Anda tinggal menunggu pemberitahuan ke rumah sakit mana pasien harus dirujuk. c. Mengirim

\section{Informasi}

Rujukan

melalui

\section{Internet/Web}

Jika di lokasi tenaga kesehatan yang akan merujuk tersedia komputer yang terhubung ke Internet, maka informasi rujukan gawat darurat dapat diinput melalui formulir yang tersedia di situs web SIJARIEMAS.

1) Nyalakan komputer, jika komputer belum menyala. Jika komputer sudah menyala, langsung ke langkah 2.

2) Sambungkan komputer ke Internet, jika belum terhubung. Apabila komputer sudah terhubung ke Internet, langsung ke Langkah 3.

3) Buka aplikasi penjelajahinternet (internet browser).

Direkomendasikan menggunakan penjelajah Mozilla Firefox.

4) Ketikkan alamat situs SIJARIEMAS kabupaten Anda di Address bar aplikasi penjelajah-internet yang digunakan. Untuk SIJARIEMAS Kabupaten ..................., alamat 
situsnya:

http://........................................

5) Login dengan username dan password user group puskesmas yang Anda miliki.

6) Klik menu Data Rujukan $\rightarrow$ Input Data Rujukan Gawat Darurat via Hotline Telepon

7) Ketikkan nomor telepon genggam tenaga kesehatan yang akan merujuk di kotak teks Nomor HP Nakes Perujuk

8) Ketikkan identitas pasien dan informasi rujukan pada kotak teks dan kotak pilihan yang tersedia

- Nama Ibu, diisi dengan nama pasien atau nama ibu bayi

- Umur, diisi umur ibu dalam tahun untuk pasien ibu atau dalam hari untuk pasien bayi

- Nama Suami, diisi nama Suami atau penanggung jawab pasien

- Golongan Darah, diisi dengan golongan darah.
Pilih dari daftar yang tersedia.

- Transportasi, diisi dengan alat transportasi yang akan digunakan untuk membawa pasien

- Diagnosa, diisi dengan diagnosa pasien

- Tindakan Pra Rujukan, diisi dengan tindakan stabilisasi yang telah dilakukan terhadap pasien sebelum pasien dirujuk

- Asuransi, diisi dengan asuransi yang digunakan. Ketik tanda "_، jika tidak menggunakan asuransi.

9) Pastikan data yang diinput sudah benar, setelah itu klik tombol Simpan.

Infomasi rujukan yang dikirim ke SIJARIEMAS akan dikirim ke rumah sakit dengan urutan aliran informasi berdasarkan setting prioritas rujukan tenaga kesehatan yang merujuk. Setelah Anda menyampaikan informasi rujukan melalui telepon, maka selanjutnya Anda tinggal 
menunggu pemberitahuan ke rumah sakit mana pasien harus dirujuk.

\section{d. Konfirmasi Kedatangan Pasien di Rumah Sakit}

Setelah permintaan rujukan yang Anda kirim melalui SIJARIEMAS diterima dan dijawab oleh salah satu rumah sakit tujuan rujukan, maka server SIJARIEMAS akan mengirimkan SMS ke nomor telepon genggam pengirim rujukan, seperti berikut:

\section{Segera rujuk pasien Siti Zulaikha ke RSUD

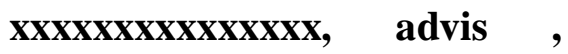 Pasang 023 ltr Per menit kanul, Infus NACL/RL 25 TPM, Jaga kestabilan. Secepatnya konfirmasi balik dgn cara ketik kr\#641}

Apabila benar bahwa pasien Siti Zulaikha pada contoh di atas akan

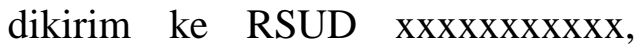
maka beritahukan ke pihak IGD rumah sakit dengan mengirim SMS konfirmasi kedatangan ke rumah sakit dengan format:

\section{kr\#id_rujukan}

Keterangan:

- kr : kata kunci untuk konfirmasi kedatangan pasien ke rumah sakit

- id_rujukan diberikan secara otomatis dari server SIJARIEMAS.

Contoh:

\section{kr\#641}

Konfirmasi bahwa pasien yang akan dirujuk akan datang ke rumah sakit juga dapat dilakukan dengan menelpon ke nomor hotline SIJARIEMAS di rumah sakit tujuan rujukan yang siap menerima dengan memberitahukan bahwa pasien dengan nomor ID_RUJUKAN tertentu akan berangkat ke rumah sakit tujuan yang siap menerima.

\section{Gambar Alur Penggunaan Rujukan SIJARIEMAS}

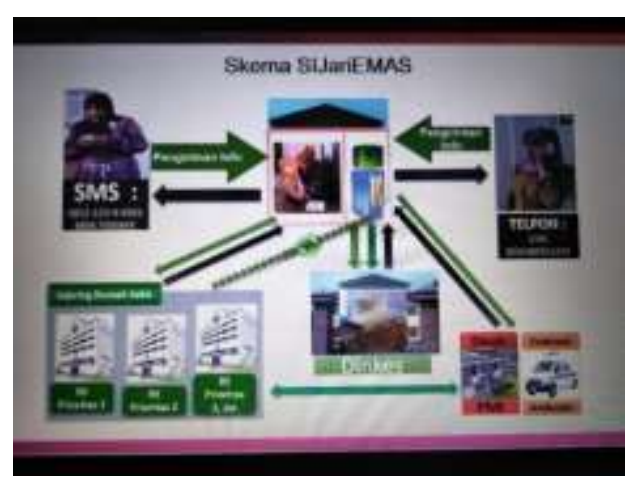




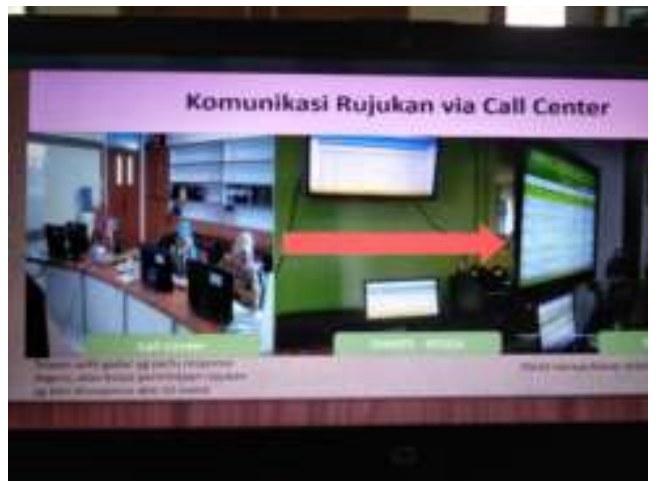

\section{e. Rumah Sakit dan Puskesmas yang bekerjasama dengan program SIJARIEMAS}

\begin{tabular}{|c|c|}
\hline muMMHSAKIT & mot \\
\hline 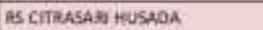 & ats \\
\hline ASA OK DNCKD PREMCENO & doto \\
\hline ASUD KAAAWANG & now \\
\hline RS FKRI MEOLA. & $4 k n$ \\
\hline AS SEMA MEDESA DELIMA ASIH & uama \\
\hline as cino & cen \\
\hline ASIRASM & islam \\
\hline AS pronlanessi & erok: \\
\hline AS KAAYYA EUSACA & tarne \\
\hline RS SARESWARI & saras \\
\hline RSA TITIAN BUNDA & wian \\
\hline as izza & 1202 \\
\hline AS PLSEIASE & suri \\
\hline AS MITMA FAMMIY & mith \\
\hline AS DEW SRE & deen 1 \\
\hline DS BANUKARTA & bane \\
\hline AS ROSELA & roset \\
\hline RS SENTRAL MEDEKA & wentra \\
\hline
\end{tabular}

\begin{tabular}{|l|l|c|l|}
\hline No & $\begin{array}{l}\text { Nama } \\
\text { Puskesmas }\end{array}$ & No & $\begin{array}{l}\text { Nama } \\
\text { Puskesmas }\end{array}$ \\
\hline $\mathbf{1}$ & $\begin{array}{l}\text { Puskesmas } \\
\text { pangkalan }\end{array}$ & 25 & $\begin{array}{l}\text { Puskesmas } \\
\text { cikampek }\end{array}$ \\
\hline $\mathbf{2}$ & $\begin{array}{l}\text { Puskesmas } \\
\text { loji }\end{array}$ & $\mathbf{2 6}$ & $\begin{array}{l}\text { Puskesmas } \\
\text { purwasari }\end{array}$ \\
\hline $\mathbf{3}$ & $\begin{array}{l}\text { Puskesmas } \\
\text { ciampel }\end{array}$ & 27 & $\begin{array}{l}\text { Puskesmas } \\
\text { tirta mulya }\end{array}$ \\
\hline 4 & $\begin{array}{l}\text { Puskesmas } \\
\text { teluk } \\
\text { jambe }\end{array}$ & 28 & $\begin{array}{l}\text { Puskesmas } \\
\text { jati sari }\end{array}$ \\
\hline 5 & $\begin{array}{l}\text { Puskesmas } \\
\text { wadas }\end{array}$ & 29 & $\begin{array}{l}\text { Puskesmas } \\
\text { pacing }\end{array}$ \\
\hline
\end{tabular}

\begin{tabular}{|c|c|c|c|}
\hline 6 & $\begin{array}{l}\text { Puskesmas } \\
\text { wanakerta }\end{array}$ & 30 & $\begin{array}{l}\text { Puskesmas } \\
\text { cicinde }\end{array}$ \\
\hline 7 & $\begin{array}{l}\text { Puskesmas } \\
\text { klari }\end{array}$ & 31 & $\begin{array}{l}\text { Puskesmas } \\
\text { gempol }\end{array}$ \\
\hline 8 & $\begin{array}{l}\text { Puskesmas } \\
\text { curug }\end{array}$ & 32 & $\begin{array}{l}\text { Puskesmas } \\
\text { kota baru }\end{array}$ \\
\hline 9 & $\begin{array}{l}\text { Puskesmas } \\
\text { cikampek } \\
\text { utara }\end{array}$ & 33 & $\begin{array}{l}\text { Puskesmas } \\
\text { tempuran }\end{array}$ \\
\hline 10 & $\begin{array}{l}\text { Puskesmas } \\
\text { cilamaya }\end{array}$ & 34 & $\begin{array}{l}\text { Puskesmas } \\
\text { lemah duhur }\end{array}$ \\
\hline 11 & $\begin{array}{l}\text { Puskesmas } \\
\text { sukatani }\end{array}$ & 35 & $\begin{array}{l}\text { Puskesmas } \\
\text { kutawaluya }\end{array}$ \\
\hline 12 & $\begin{array}{l}\text { Puskesmas } \\
\text { pasir } \\
\text { rukem }\end{array}$ & 36 & $\begin{array}{l}\text { Puskesmas } \\
\text { kutamukti }\end{array}$ \\
\hline 13 & $\begin{array}{l}\text { Puskesmas } \\
\text { bayur lor }\end{array}$ & 37 & $\begin{array}{l}\text { Puskesmas } \\
\text { dengklok }\end{array}$ \\
\hline 14 & $\begin{array}{l}\text { Puskesmas } \\
\text { lemah } \\
\text { abang }\end{array}$ & 38 & $\begin{array}{l}\text { Puskesmas } \\
\text { kalangsari }\end{array}$ \\
\hline 15 & $\begin{array}{l}\text { Puskesmas } \\
\text { telagasari }\end{array}$ & 39 & $\begin{array}{l}\text { Puskesmas } \\
\text { medangasem }\end{array}$ \\
\hline 16 & $\begin{array}{l}\text { Puskesmas } \\
\text { majalaya }\end{array}$ & 40 & $\begin{array}{l}\text { Puskesmas } \\
\text { jayakerta }\end{array}$ \\
\hline 17 & $\begin{array}{l}\text { Puskesmas } \\
\text { plawad }\end{array}$ & 41 & $\begin{array}{l}\text { Puskesmas } \\
\text { pedes }\end{array}$ \\
\hline 18 & $\begin{array}{l}\text { Puskesmas } \\
\text { adiarsa }\end{array}$ & 42 & $\begin{array}{l}\text { Puskesmas } \\
\text { sungai buntu }\end{array}$ \\
\hline 19 & $\begin{array}{l}\text { Puskesmas } \\
\text { karawang } \\
\text { kota }\end{array}$ & 43 & $\begin{array}{l}\text { Puskesmas } \\
\text { kertamukti }\end{array}$ \\
\hline 20 & $\begin{array}{l}\text { Puskesmas } \\
\text { tungak jati }\end{array}$ & 44 & $\begin{array}{l}\text { Puskesmas } \\
\text { cibuaya }\end{array}$ \\
\hline 21 & $\begin{array}{l}\text { Puskesmas } \\
\text { nagasari }\end{array}$ & 45 & $\begin{array}{l}\text { Puskesmas } \\
\text { tirtajaya }\end{array}$ \\
\hline 22 & $\begin{array}{l}\text { Puskesmas } \\
\text { tanjung } \\
\text { pura }\end{array}$ & 46 & $\begin{array}{l}\text { Puskesmas } \\
\text { batujaya }\end{array}$ \\
\hline 23 & $\begin{array}{l}\text { Puskesmas } \\
\text { rawamerta }\end{array}$ & 47 & $\begin{array}{l}\text { Puskesmas } \\
\text { pakis jaya }\end{array}$ \\
\hline
\end{tabular}




\begin{tabular}{|l|l|l|l|}
\hline 24 & $\begin{array}{c}\text { Puskesmas } \\
\text { balongsari }\end{array}$ & 48 & Puskesmas \\
\hline
\end{tabular}

f. Sarana dan Prasarana yang di butuhkan

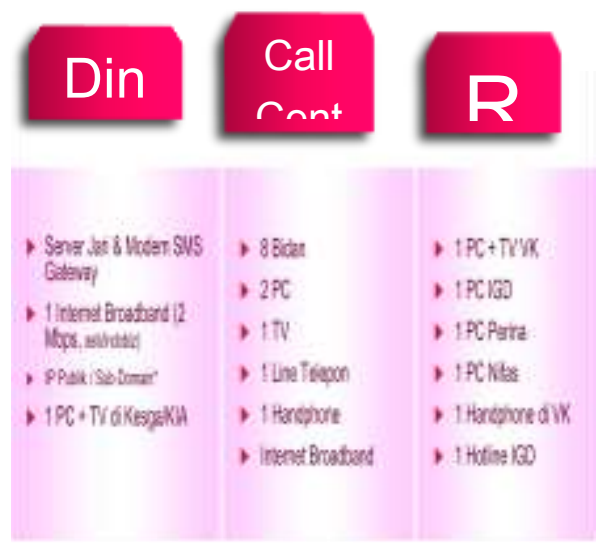

\section{KESIMPULAN}

Berdasarkan hasil penelitian dan pembahasan maka dapat disimpulkan hasil dari penelitian sebagai berikut:

1. Program EMAS dibuat dan disepakati bersama antara Program EMAS,USAID, Kementerian Kesehatan RI, Dinas Kesehatan Provinsi dan Organisasi Profesi terkait. Dalam pelaksanaannya pendampingan Program EMAS dilaksanakan oleh 5 organisasi yang mendapatkan mandate, yaitu Jhpiego, afiliasi Johns Hopkins University, Rumah Sakit Budi Kemuliaan, Organisasi Islam Muhammadiyah, Save The
Children dan Research Triangle Institute (RTI). Ke 5 organisasi tsb, melalui staf yang bekerja di Program EMAS Provinsi Jawa Barat, bekerjasama dgn DinasKesehatan Provinsi Jawa Barat, Pemda Provinsi Jawa Barat, Organisasi Profesi terkait di Provinsi Jawa Barat dan stakeholders lainnya yang tergabung dalam Tim Koordinasi Penyelamatan Ibu dan bayi baru lahir Provinsi Jawa Barat (SK Gubernur Jawa Barat no 441.8/Kep.1076-Dinkes/2014), memilih Kabupaten kabupaten dengan jumlah kematian Ibu dan bayi yang tinggi, serta memiliki sumberdaya yang cukup dan komitmen pemda setempat yang tinggi, untuk dijadikan sebagai Kabupaten percontohan yang akan mendapatkan pendampingan dari program EMAS, dimana salah satunya adalah Kabupaten Karawang.

2. Komunikasi dalam sistem rujukan memegang peranan penting. Terkait dengan penyampaian rujukan gawatdarurat, komunikasi antara 
tenaga kesehatan perujuk (dokter/bidan/perawat) dengan petugas kesehatan di IGD tempat tujuan rujukan juga sangat penting. Pihak perujuk harus menyampaikan informasi yang benar tentang pasien, diagnosis yang tepat, dan tindakan prarujukan kepada petugas IGD. Di pihak lain, Petugas IGD Rumah Sakit juga harus memberikan advis stabilisasi yang baik dan benar kepada petugas kesehatan perujuk, sesuai standar prosedur operasional.

Dalam pemanfaatan SIJARIEMAS, komunikasi didukung dengan media SMS, telepon, dan Internet. Komunikasi dengan SMS dan Internet memungkinkan informasi langsung tercatat atau tersimpan di dalam sistem. Penggunaan SMS seringkali kurang fleksibel karena butuh waktu untuk mengetik teks serta menunggu proses pengiriman dan balasan. Sedangkan komunikasi menggunakan telepon tidak langsung tercatat/terekam atau tersimpan, namun proses komunikasi bisa lebih cepat dan fleksibel (antara lain bisa dikerjakan sambil tangan kita melakukan hal lain). Karena media yang digunakan dalam SIJARIEMAS memiliki kelebihan dan kekurangan masing-masing, maka dalam prakteknya semua media komunikasi harus digunakan untuk saling mendukung, termasuk penggunaan media komunikasi lain sebagai pendukun.

\section{DAFTAR PUSTAKA}

\section{A. BUKU-BUKU}

Burhan Ashofa, Metode Penelitian Hukum, Rieneka Cipta, Jakarta, 2002.

Soejorno Soekanto dan Sri Madmudji, Penelitian Hukum Normatif, Suatu Tinjauan Singkat, Rajawali, Jakarta 1985.

Soekidjo Notoatmodjo,

Metodologi Penelitian

Kesehatan, Rineka Cipta, Jakarta,2005.

Yanti dan Nurul Eko, Etika Profesi kesehatan, Pustaka Rihama, Yogyakarta, 2010 


\section{B. SUMBER LAIN}

SK Gubernur Jawa Barat no 441.8/Kep.1076-Dinkes/2014

Doc Dinkes Karawang Buku I,

Pengantar SIJARIEMAS.

Doc Dinkes Karawang Buku II,

Pedoman Langkah-langkah

Penggunaan SIJARIEMAS.

http://www.medanbisnisdaily.com

/news/read/2013/03/20/18924

/program-emas-bentuk-rac/

http://m.liputan6.com/health/read/

475795/kematian-ibu-dan-

anak-di-jawa-barat-masih-

yangtertinggi 
